\title{
Comment
}

\section{Insulin Degradation by Adipose Tissue Is Increased in Human Obesity*}

\author{
IMMACULADA RAFECAS, JOSÉ-ANTONIO FERNANDEZ-LOPEZ, ISABEL SALINAS, \\ XAVIER FORMIGUERA, XAVIER REMESAR, MÀIUS FOZ, AND MARIA ALEMANY
}

Departament de Bioquímica i Fisiologia, Universitat de Barcelona (I.R., J.-A.F.-L., X.R., M.A.), Barcelona, Spain; and Secció d'Endocrinologia (L.S.) and Unitat de Trastorns de l'Alimentació (X.F., M.F.), Departament de Medicina Interna, Hospital Universitari Germans Trias i Pujol, Badalona, Spain

\begin{abstract}
White adipose tissue samples from obese and lean patients were used for the estimation of insulin protease and insulin:glutathione transhydrogenase using ${ }^{125}$ I-labeled insulin. There was no activity detected in the absence of reduced glutathione, which indicates that insulin is cleaved in human adipose tissue through reduction of the disulfide bridge between the chains. Obese patients showed higher transhydrogenase activity (per $U$ tissue protein wt, per $U$ tissue wt, and in the total adipose tissue mass) than the lean group. There is a significant correlation between the activity per $U$ tissue
\end{abstract}

wt, and protein and total activity in the whole adipose tissue with respect to body mass index, with a higher activity in obese patients. The potential of insulin cleavage by adipose tissue in obese patients was a mean 5.6-fold higher than that in controls. The coexistence of high insulinemia and high cleavage capability implies that insulin secretion and turnover are increased in the obese. Thus, white adipose tissue may be crucial in the control of energy availability through modulation of insulin cleavage. (J Clin Endrocrinol Metab 80: $693-695,1995$ )
$\mathrm{O}^{\mathrm{s}}$ BESITY is often characterized by hyperinsulinemia, which has a direct bearing on the increased lipid accrual in obese individuals, insulin resistance, and lateonset diabetes (1). Because hepatic disposal of insulin is decreased in obesity (2), we attempted to investigate whether this trend was also observed in adipose tissue, as its large mass in the obese may influence peripheral insulin degradation to a greater extent than in individuals with normal fat depots.

The half-life of circulating insulin is short, in the range of minutes, although its functional turnover may be somewhat longer in normal weight humans, because it is rapidly taken up and inactivated by liver $(3,4)$, adipose tissue $(5)$, and muscle $(5,6)$. Insulin may be inactivated through internalization after interacting with its receptor (7), but most of it is cleaved by specific systems through a selective proteolytic pathway (4) or by means of the more commonly accepted reduction of the disulfide bridge between the $\alpha$ - and $\beta$-chains $(3,5)$. This reaction is catalyzed by insulin:glutathione transhydrogenase (EC 1.8.4.2) $(3,5)$, with glutathione providing the reducing power.

Received April 8, 1994. Revision received October 4, 1994. Accepted October 11, 1994.

Address all correspondence and requests for reprints to: Prof. Dr. Marià Alemany, Departament de Bioquímica i Fisiologia, Facultat de Biologia, Universitat de Barcelona, Av. Diagonal 645, 08028 Barcelona, Spain.

* This work was supported by Grant DEP91-0736 from the Plan Nacional de Investigación Científica y Desarrollo Tecnologico of the Government of Spain.

\section{Materials and Methods}

Samples of sc abdominal white adipose tissue were obtained from patients undergoing laparotomy because of hernia $(n=5)$ or cholecystectomy ( $n=3$ ), control group; five men and three women; body mass index (BMI), $<27 \mathrm{~kg} / \mathrm{m}^{2}$; or obese patients (BMI, $>30 \mathrm{~kg} / \mathrm{m}^{2}$ ) subjected to laparotomy because of cholecystectomy $(n=1)$ or vertical-banded gastroplasty ( $\mathrm{n}=9$; seven women and three men). None of the women included in the experiment had reached menopause; patients receiving medication were not used in the study. Informed consent of the patients and of the Clinical Assays Committee was obtained prior to the undertaking of the experiments. The parameters defining the two groups of patients studied are presented in Table 1. Blood was extracted in the morning after an overnight fast; the -samples were used for the measurement of glycemia (8) and insulinemia (through radioimmunoanalysis; Diagnostic Products Corp., Los Angeles, CA). Pieces of adipose tissue $(\sim 2 \mathrm{~g})$ were dissected from the abdominal sc fat masses near the surgical wound; they were immediately frozen in liquid nitrogen after extraction and kept under liquid nitrogen or in deep freeze $(-80 \mathrm{C})$ until processed. Aliquots of about $0.5 \mathrm{~g}$ tissue were weighed and homogenized with a Polytron tissue disrupter (Kinematica, Luzern, Switzerland) in $10 \mathrm{vol}$ chilled $50 \mathrm{mmol} / \mathrm{L}$ phosphate buffer, pH 7.5, containing $250 \mathrm{mmol} / \mathrm{L} \mathrm{su}$ crose. The homogenates were centrifuged for $10 \mathrm{~min}$ at $5000 \times \mathrm{g}$, and the supernatant layer of fat and the pellet were discarded; the clear homogenate was used for the estimation of insulin:glutathione transhydrogenase, using ${ }^{125}$ I-labeled insulin (Amersham, UK) with the method of Thomas and Varandani (9). A set of determinations was carried out by omitting the reduced glutathione, as this experimental set-up has been used to measure insulin protease (10). Protein in homogenates was estimated with the Lowry method (11).

The degree of interrelationship between data was estimated by establishing the linear correlation coefficient for paired parameters. Comparison between groups was performed with Student's $t$ test. 
TABLE 1. Insulin:glutathione transhydrogenase activity in white adipose tissue of lean controls and morbid obese patients

\begin{tabular}{lccc}
\hline \multicolumn{1}{c}{ Parameter } & Control & $P^{a}$ & Obese \\
\hline Age (yr) & $55.5 \pm 6.4$ & NS $^{b}$ & $40.3 \pm 4.6$ \\
BMI (kg/m ${ }^{2}$ ) & $25.3 \pm 1.0$ & $<0.05$ & $45.1 \pm 4.4$ \\
BW (kg) & $67.0 \pm 4.5$ & $<0.05$ & $117.9 \pm 11.8$ \\
Lean body mass (kg) & $46.3 \pm 2.1$ & $<0.05$ & $59.2 \pm 4.4$ \\
Fat tissue mass (kg) & $20.6 \pm 2.7$ & $<0.05$ & $58.7 \pm 9.7$ \\
Glycemia (mmol/L) & $5.5 \pm 0.3$ & NS & $7.0 \pm 0.9$ \\
Insulinemia (pmol/L) & $106 \pm 23$ & $\mathrm{NS}$ & $198 \pm 57$ \\
Insulin cleaving activity: & & & \\
$\quad$ Per g tissue (pkat/g) & $2.01 \pm 0.51$ & $<0.05$ & $4.35 \pm 0.40$ \\
$\quad$ Per g protein (pkat/g) & $161 \pm 38$ & $<0.05$ & $398 \pm 59$ \\
$\quad$ In the whole adipose tissue & $42.8 \pm 12.1$ & $<0.05$ & $243.5 \pm 43.4$ \\
$\quad$ (nkat) & & & \\
\hline
\end{tabular}

The values presented are the mean \pm SEM for each group, controls ( $n=8$; three women and five men) and obese $(n=10$; three men and seven women). Glycemia and insulinemia were measured under basal conditions. Lean and fat tissue mass were calculated according to the method of Garrow (12).

${ }^{a}$ Statistical significance of the differences between groups.

${ }^{b} P>0.05$.

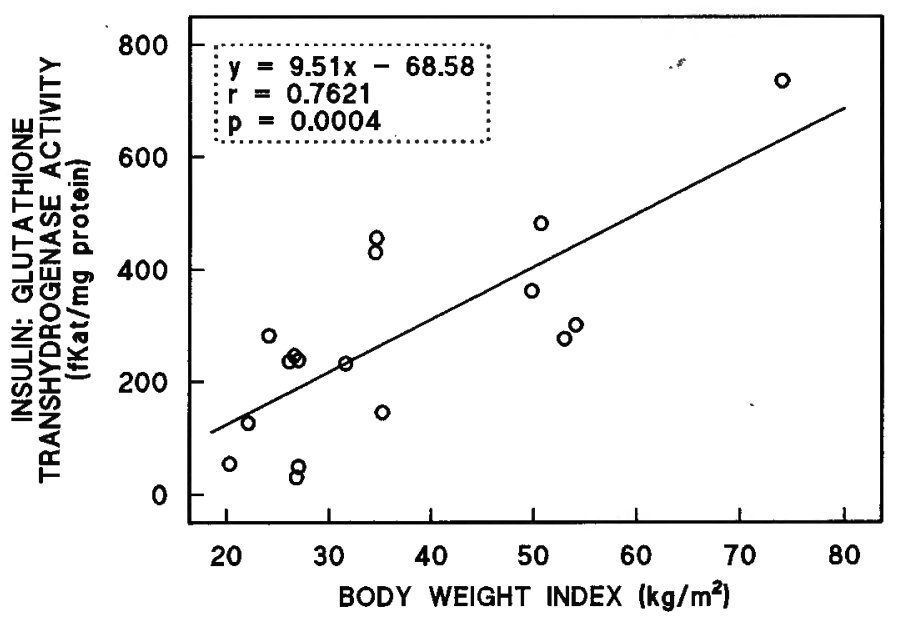

FIG. 1. Insulin:glutathione transhydrogenase activity in human adipose tissue as a function of BMI.

\section{Results}

Table 1 shows the mean insulin:glutathione transhydrogenase activity in the adipose tissue samples of both groups. The activity found in the absence of reduced glutathione was nil in all samples, which indicates that the mode of cleavage of insulin by human adipose tissue is the reduction of the disulfide bridge between the chains. Obese patients showed higher enzyme activity (per U tissue protein wt, per $U$ tissue $w t$, and in the total adipose tissue mass) than the lean group.

The differences in glycemia and insulinemia between the two groups of patients were not significant; the two sets of data were highly correlated $(r=0.704 ; P=0.005)$, although neither was significantly correlated with BMI.

Figure 1 shows the relationship between insulin-cleaving activity in white adipose tissue and BMI. There was a significant correlation between the activity, both per $U$ tissue wt $(r=0.616 ; P=0.015)$ and protein $(r=0.762 ; P=0.000)$, with respect to $\mathrm{BMI}$, and there was a greater activity in obese patients. The weight, height, and sex data of all patients were used to obtain a rough estimate of the lean body and adipose tissue mass of each patient (12). This allowed calculation of the combined adipose tissue insulin:glutathione transhydrogenase in each individual. The data plotted against BMI again gave a high coefficient of correlation $(r=0.928 ; P=$ 0.000 ), showing a strong relationship between total adipose tissue insulin-cleavage activity and BMI. This is a combined effect of higher activity per $U$ tissue weight and higher mass of adipose tissue. As a result, the potential for insulin cleavage of the patients in the obese group was a mean 5.6-fold higher than that of lean controls.

\section{Discussion}

There may be a conflict between the insulin levels in the obese and the supposedly higher peripheral cleavage potential found. High insulinemia may be a consequence of either increased insulin synthesis or decreased cleavage; because in the obese subjects, both high circulating insulin levels and high rates of insulin destruction coexist, it is implied that in obesity there is increased insulin secretion within a context of insulin resistance. The result is increased insulin turnover in the obese, as has been observed in Zucker obese rats (Cañas X., J. A. Fernández-López, A. Ardérol, C. Adán, I. Rafecas, X. Remesar and M. Alemany, unpublished results). The increased insulin secretion may be instrumental in the age-linked loss of function and onset of type II diabetes observed late in life of many obese people (1).

Insulin degradation in the liver of the obese is diminished (2), which may help to explain the hyperinsulinemia often associated with obesity (1). However, the grossly increased peripheral (adipose tissue) ability to degrade insulin observed here may more than compensate for the splanchnic fall in insulinase activity. This higher ability to cleave insulin by the obese may be interpreted as a counter-mechanism to limit hyperinsulinemia. A possible succession of events in the obese may include the development of insulin resistance, which results in hyperinsulinemia; this, in turn, may induce the increase in peripheral insulin cleavage found here, which could help prevent an excessive rise in insulin at the expense of a higher turnover rate.

The results presented suggest that white adipose tissue may be more crucial to the control of energy availability and deposition than currently assumed, not only through lipid synthesis and storage, but also as a critical modulator of insulin levels, a prime element in the control of the fate of available energy substrates.

\section{Acknowledgments}

We thank the Departament de Cirurgia of the Hospital Universitari Germans Trias i Pujol for providing tissue and blood samples, and Robin Rycroft for editorial assistance.

\section{References}

1. Bonnadona RC, DeFronzo RA. 1992 Glucose metabolism in obesity and type II diabetes. In: Björntorp $\mathrm{P}$, Brodoff $\mathrm{BN}$, eds. Obesity. Philadelphia: Lipincott; 474-501. 
2. Björntorp P. 1988 Abdominal obesity and the development of noninsulin-dependent diabetes mellitus. Diabetes/Metab Rev. $4: 615-622$

3. Varandani PT. 1974 Insulin degradation. VI. Feedback control by insulin of liver glutathione-insulin transhydrogenase in rat. Diabetes. 23:117-125.

4. Duckworth WC, Hamel FG, Peavy DE, et al. 1988 Degradation products of insulin generated by hepatocytes and by insulin protease. J Biol Chem. 263:1826-1833.

5. Chandler M, Varandani PT. 1972 Insulin degradation. II. The widespread distribution of glutathione-insulin transhydrogenase in the tissues of the rat. Biochim Biophys Acta. 286:136-145.

6. Neal GW, Kitabchi AE. 1982 Insulin degradation by human skeletal muscle. Biochim Biophys Acta. 719:259-266.

7. Terris S, Steiner DF. 1975 Binding and degradation of ${ }^{125} \mathrm{I}$-insulin by rat hepatocytes. J Biol Chem. 250:8389-8398.
8. Trinder P. 1969 Determination of glucose in blood using glucose oxidase with an alternative oxygen acceptor. Ann Clin Biochem. $6: 24-27$.

9. Thomas JH, Varandani PT. 1979 Insulin degradation. XXV. Glutathione-insulin transhydrogenase activity of rat liver and kidney during the development of streptozocin-diabetes. Biochim Biophys Acta. 567:88-95.

10. Hern EP, Shroyer LA, Varandani PT. 1987 Insulin-degrading neutral cysteine proteinase activity of adipose tissue, and liver of nondiabetic, streptozotocin-diabetic, and insulin-treated diabetic rats. Arch Biochem Biophys. 254:35-42.

11. Lowry OH, Rosebrough N, Farr A, Randall RJ. 1951 Protein measurement with the Folin phenol reagent. J Biol Chem. 193:265-275.

12. Garrow JS. 1988 Measurement of energy stores. In: Garrow JS, ed. Obesity and related diseases. Edinburgh: Churchill Livingstone; $25-52$.

\section{Diabetes Forum Italy '95}

Immunology of Diabetes $95^{\prime}$ : 14th International Immunology and Diabetes Workshop and 1st meeting of the Immunology of Diabetes Society

This meeting will be held October 31-November 3, 1995, in Rome, Italy, Main topics: genetics, pathogenesis, prediction, prevention and immunotherapy of type 1 diabetes in man and animals. Oral and poster presentations will be selected among the submitted abstracts. The meeting will be characterized by smaller group workshops, a "stop press" session, special sessions on autoantibody workshop results and by plenty of time for discussion. For more information, abstract and registration forms please contact: Prof Umberto Di Mario, DEM Foundation, Largo Marchiafava 1, 00161 Rome, Italy, Tel. + 3964463605 (or 4468333), Fax + 396 4469190 (or 44291464).

Lessons from Animal Diabetes: 5th International Meeting

This meeting will be held October 29-31, 1995, in Rome, Italy, Main topics: animal models of type 1 diabetes, transgenic animals, diabetic complications, therapeutic intervention. For more information, abstract, and registration forms please contact the secretariat: DEM Foundation, Largo Marchiafava 1, 00161 Rome, Italy, Tel. + 3964463605 (or 4468333), Fax + 3964469190 (or 44291464).

Beta-cell, Islet, and Pancreas Transplants

This meeting will be held November 3-4, in Rome, Italy. Main topics: xenotransplatation, encapsulation, clinical trials, immunosuppressive therapy, immune response, host immunization related to beta-cell, islet and pancreas transplants. For more information, abstract and registration forms please contact the secreatariat: DEM Foundation, Largo Marchiafava 1, 00161 Rome, Italy, Tel. + 3964463605 (or 4468333), Fax + 3964469190 (or 44291464).

\section{Immunology of Diabetic Pregnancy: 2nd International Meeting}

This meeting will be held November 5-7, 1995, in Erice (Sicly), Italy. Main topics: aspects of the immunobiology of normal and diabetic pregnancy. For more information, abstract, and registration forms please contact: Prof A Galluzzo, DEM Foundation, Largo Marchiafava 1, 00161 Rome, Italy, Tel. + 3964463605 (or 4468333), Fax +3964469190 (or 44291464). 